\title{
Method and Mechanism of Dump Overlying the Bedrock with Large Dip Angle in Opencast Mine
}

\author{
Hongze Zhao $\mathbb{D}^{1},{ }^{1,2}$ Hairui Du $\mathbb{D}^{1},{ }^{1}$ Zhigang Tao $\mathbb{D}^{2},{ }^{2}$ and Zechen Lin $\mathbb{D D}^{1}$ \\ ${ }^{1}$ School of Energy and Mining Engineering, China University of Mining and Technology (Beijing), Beijing 100083, China \\ ${ }^{2}$ State Key Laboratory for Geomechanics and Deep Underground Engineering, \\ China University of Mining and Technology (Beijing), Beijing 100083, China
}

Correspondence should be addressed to Hongze Zhao; hzzhao78@163.com

Received 2 December 2020; Revised 2 April 2021; Accepted 16 May 2021; Published 2 June 2021

Academic Editor: Chunshun Zhang

Copyright ( $\odot 2021$ Hongze Zhao et al. This is an open access article distributed under the Creative Commons Attribution License, which permits unrestricted use, distribution, and reproduction in any medium, provided the original work is properly cited.

\begin{abstract}
Dump in the steep area of the open-pit mine is essential for safe production. The bedrock with the bumpy-surface blasting method effectively improves the stabilization of the dumpsite. The effect of the ratio and dispersion degree on the deformation and failure of the dumping bench at the largely inclined area was analyzed. Based on the limit equilibrium method, the equation about the stability factor and the blasted region ratio was deduced. Virtual experiments were performed to address how the ratio and dispersion degree affect deformation and failure. The results showed that the stability factor is a quadratic function of the ratio of the blasted area. The increase in the ratio results in a drastic reduction of displacement, and the direction of displacement significantly changes. The rise in the dispersion degree effectively reduces the displacement and shear strain increment, and the failure mode changes. There is a specific value for the ratio and dispersion degree, making the displacement and shear strain increment little. The research on bumpy surface blasting in this paper provides the theoretical foundation for the dump construction at the site with the large dip angle.
\end{abstract}

\section{Introduction}

The occurrence of coal seams in open-pit mining is mainly horizontal, near-horizontal, and gently inclined and that of the inner dump basement is consistent with the coal seams [1]. The complex geological structure is not propitious for mining [2]. The dumping work line encounters a steep anticline, the inclination angle of basement increases sharply, and the resistant and sliding forces are changed; the former increases and the latter decreases [3]. The dump stability significantly reduces and is prone to bedding landslide. The basement topography easily affects stability [4]. Lanni et al. [5] adopted Darcy's equation and cellular model to find that the bedrock depression could easily result in increased pore water pressure in the local zones. Moradi et al. [6] found that bedrock topography would affect groundwater distribution and pore water pressure, and variable bedrock topography significantly affected slope stability. Gomes et al. [7] evaluated the marginal and joint effects of uncertainty in bedrock depth and hydraulic characteristics using the Monte Carlo method, which significantly increased slope failure probability. Through a set of centrifugal experiments, Zhao et al. [8] discovered that the failure modes were different due to the difference of inclination and roughness. According to the geological survey, Clarke and Burbank [9] found that bedrock depth controlled the morphology, scale, and frequency of the landslide. Miraboutalebi et al. [10] found out that the increase of bedrock inclination would make the acceleration and displacement of the sliding body reach the maximum with the mean period of the acceleration time history on the failure surface close to the predominant period of the slope. Mahanta et al. [11] found that there were five failure modes of landfill built on inclined substrates. Retaining walls and textured geomembrane could effectively improve the stability of landfills. Stark et al. [12] studied that excavating the toe of the slope resulted in sliding with deep bedrock along the plane. Engineering measures should be taken to improve 
dump stability and make the slope stable in the service period, including load reduction at the top of the slope, compression at the foot of the slope, anchoring, retaining, and modifying the base topography [13]. Liu et al. [14] indicated that bedrock dip angle and contact surface internal friction angle jointly affected dump stability, based on which whether dump in the self-locking or unlocked state can be determined. The overturning moment of the upper structure increases with the dip angle increasing. Morphological variations resulted in deformation differences in different regions. The steep, curved, narrow topography can significantly affect the sliding rate. Wang et al. [15] believed that except for the coal pillar length, the increase of top width, bottom angle, and height is conducive to improving the supporting effect. Sorochan and Puzrin [16] analyzed the relationship between the optimal anchor hole position, the maximum tension of the anchor cable, and the inclination angle through algebraic equations. Based on the Bishop method, Rakishev et al. [17] analyzed the variation of slope angle and dumping height with different inclined angles of bedrock. Dong and Zhang [18] successfully employed the bumpy surface blasting method to solve the dump instability problem in Haizhou Open-Pit Mine, China. The principle is to increase the contact surface friction by blasting. Previous studies mainly solved the blasting parameters problem of the method and did not analyze the deformation and failure mechanism of the dump with large inclined bedrock from the perspective of the area ratio and dispersion degree, the effect of which on deformation and mechanism was investigated combined with dump at Lu Zigou anticline in Anjialing Open-Pit Mine.

\section{The Construction of Dump at Steep Region}

2.1. The Method of Dumping. The sliding force of dump constructed at the inclined area is larger than that of the horizontals or near-horizontals, and the resistant force decreases. Therefore, the dump stability can be improved by increasing the friction between bedrock and dump through changing the bedrock shape or retaining coal pillars and confining the end slope. Due to the large inclination angle, the dumpsite development method is dumping with a step in a region, as shown in Figure 1. The literature [18] proposed a method to improve the dump stability, namely, bumpy surface blasting. The principle is that the sliding surface is changed into an uneven shape to increase the frictional force of the sliding surface through blasting. The method is characterized by the economy, safety, and little influence on production. In the large dip area, in order to ensure sufficient and reliable space of inner dump and assure the feasibility of pitted blasting, when the coal steps are broken at the deepest part of the stope, the blasting hole should be more in-depth than the generals, and the rock of base near the borehole was slightly and only broken. After the coal is mined, the dump is constructed in the area, as shown in Figure 2.

2.2. Simplified Model and Mechanical Analysis. The dump is simplified as follows: the bolt dot-dash line of the line $A B$ represents the blasted area. The length of the interface between the step and the substrate is 1 , the inclination of the base is $\alpha$, the natural resting angle of the soiled step is $\beta$, and the height of the step is $H$. Taking the dotted line $\mathrm{CD}$ in the figure as a boundary, the triangle $\mathrm{ABC}$ is divided into two parts: triangles $\mathrm{ADC}$ (I) and $\mathrm{CDB}$ (II), and then the two parts are divided into vertical strips by the slice method, the simplified dump is shown in Figure 3(a).

For I and II regions, the height of any strip is

$$
\begin{aligned}
& \Delta y_{1}=x(\tan \beta-\tan \alpha), \\
& \Delta y_{2}=H-x \tan \alpha .
\end{aligned}
$$

There is gravity $G_{i}$ at the center of the strip, $E_{i-1}$ as the supporting force from the next strip acts on the left boundary, $E_{i}$ as the push of the previous on the right, $N_{i}$ as the supporting force of the bedrock, and $R_{i}$ as the antisliding force of the interface, as illustrated in Figure 3(b).

The gravity of a strip at I zone

$$
G_{1 i}=x(\tan \beta-\tan \alpha) d x \gamma,
$$

where $i$ is the ID of strip, $i=1,2,3, \ldots, n$.

The supporting force is

$$
N_{1 i}=G_{1 i} \cos \beta=x(\tan \beta-\tan \alpha) \gamma \cos \alpha \mathrm{d} x,
$$

and the resistance forces of the strip located in the blasted and original area are, respectively,

$$
\begin{aligned}
& R_{1 i}^{\prime}=c^{\prime} \mathrm{d} x+N_{i} \tan \varphi^{\prime}=c^{\prime} \mathrm{d} x+x \mathrm{~d} x P \tan \varphi^{\prime}, \\
& R_{1 i}^{0}=c^{0} \mathrm{~d} x+N_{1 i} \tan \varphi^{0}=c^{0} \mathrm{~d} x+x \mathrm{~d} x P \tan \varphi^{0} .
\end{aligned}
$$

Dividing the blasted and nonblasted area into a group, and setting the length of the group as $l_{j}$, in which antisliding force of strips is, respectively,

$$
\begin{aligned}
& R_{1 j}^{\prime}=-\frac{\left(k l_{j}\right)^{2}}{2} P \tan \varphi^{\prime}+k l_{j}\left(c^{\prime}+x_{j} P \tan \varphi^{\prime}\right), \\
& R_{1 j}^{0}=\frac{\left(k l_{j}\right)^{2}}{2} P \tan \varphi^{0}-k l_{j}\left(c^{0}+x_{j} P \tan \varphi^{0}\right)+l_{j} c^{0}+\left(l_{j} x_{j}-\frac{l_{j}^{2}}{2}\right) P \tan \varphi^{0},
\end{aligned}
$$




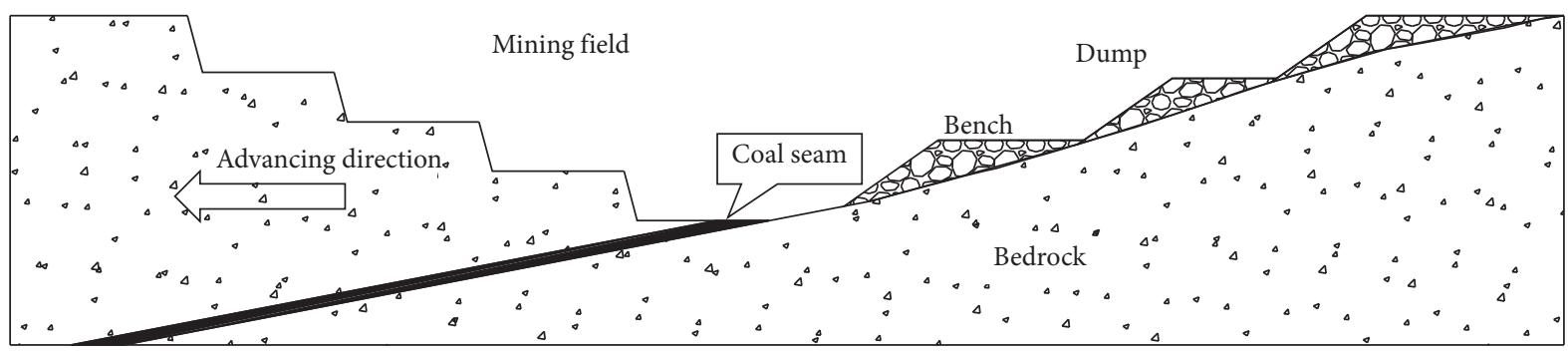

FIgure 1: The method of dump at the zone with large dip angle.

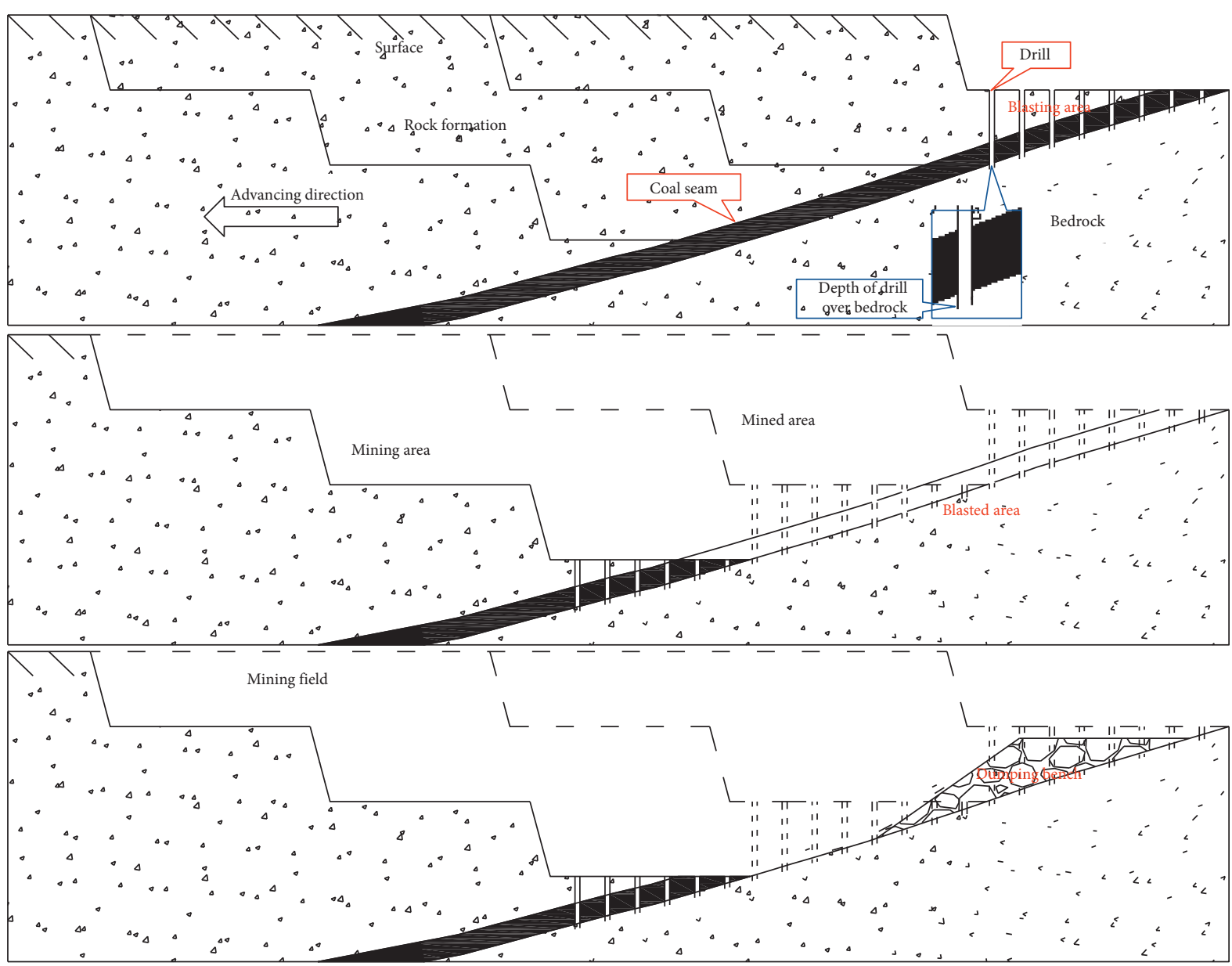

Figure 2: Bumpy surface blasting.

where $P=(\tan \beta-\tan \alpha) \gamma \cos \beta, k \in[0,1], k$ is a proportion of the blasted area, $j$ is the amount of group, $j=1,2,3, \ldots$, $2 \mathrm{~m}$, also means dispersion degree, and $x_{\mathrm{j}}$ is the location of the boundary of the blasted group.
By adding equations (7) and (8), the resistant force of a group can be calculated:

$$
R_{1 j}=-\frac{\left(k l_{j}\right)^{2}}{2} P\left(\tan \phi^{\prime}-\tan \phi^{0}\right)+k l_{j}\left[\Delta c+x_{j} P\left(\tan \phi^{\prime}-\tan \phi^{0}\right)\right]+l_{j} c^{0}+\left(l_{j} x_{j}-\frac{l_{j}^{2}}{2}\right) P \tan \phi^{0}
$$

Similarly, the resistant force of a group in zone II can be counted: 


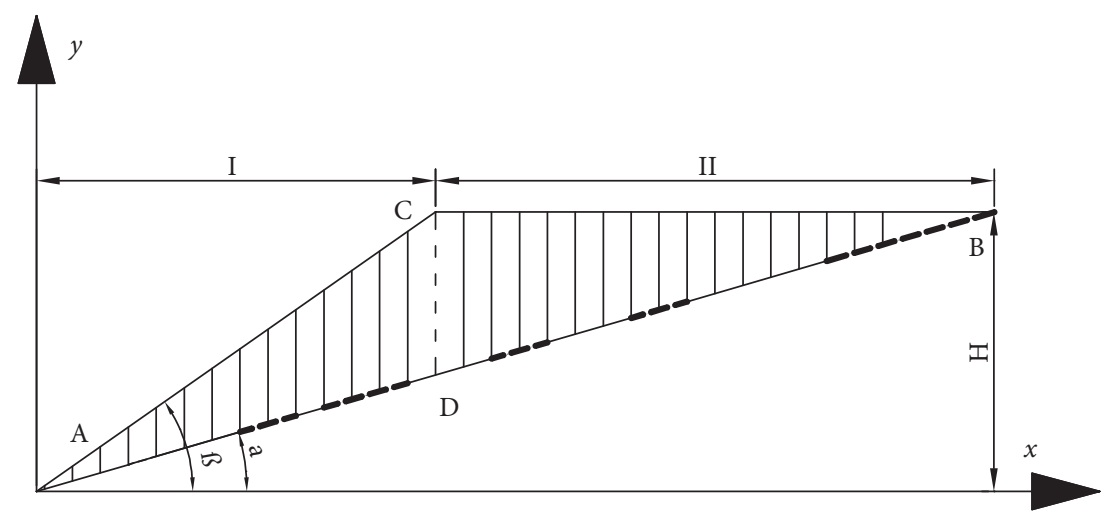

(a)

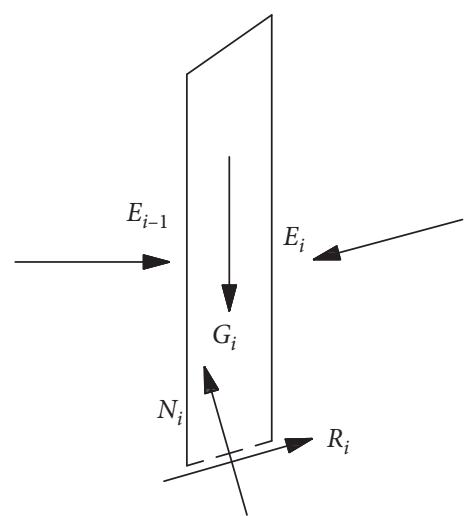

(b)

Figure 3: Dump step strip division. (a) Simplified model. (b) Stress of strip.

$$
\begin{aligned}
R_{2 j}= & \frac{\left(k l_{j}\right)^{2}}{2} \tan \alpha Q\left(\tan \phi^{\prime}-\tan \phi^{0}\right)+k l_{j}\left[\Delta c+Q\left(\tan \phi^{\prime}-\tan \phi^{0}\right)\left(H-x_{j} \tan \alpha\right)\right] \\
& +\left[H l_{j}-\left(l_{j} x_{j}-\frac{l_{j}^{2}}{2}\right) \tan \alpha\right] Q \tan \phi^{0}+l_{j} c^{0},
\end{aligned}
$$

where $Q=\gamma \cos \beta$.

By equations (9) and (10), the resistant forces in I and II are both the unitary quadratic function with $k$ and the linear function with $x$, as shown in Figures 4 and 5, respectively.

For $j$ group, the remaining slipping force

$$
E_{1 j}=W_{1 j}-R_{1 j}+E_{1 j-1},
$$

where $W_{1 j}=\left(l_{j} x_{j}-\left(l_{j}^{2} / 2\right)\right) P \sin \alpha, W_{1 j}$ has nothing to do with $k$, and $R$ and $W$ are linear functions of $x$, so the residual slip force is a quadratic function of $k$ and linear function with $x$. There is no external force on the dumping steps, and the factor of stability $\left(F_{s}\right)$ of the dump step is as follows:

$$
F_{s}=\frac{1}{\sum_{j=1}^{m} W_{1 j}+\sum_{j=m+1}^{2 m} W_{2 j}} \cdot\left(\sum_{j=1}^{m} R_{1 j}+\sum_{j=m+1}^{2 m} R_{2 j}\right),
$$

with $\sum_{j=1}^{2 m} E_{j}=0$.

\section{A Case Analysis}

3.1. Overview of Lu Zigou Anticline. The Ping Shuo mining area is located in Shuo Zhou City, Shanxi Province, China. There are three faults and two collapse columns, as well as two folds at $1^{\text {st }}$ mining area. The height of the mining bench is $15 \mathrm{~m}$. The elevation of dump is $1270 \mathrm{~m}$. Faults including $F_{23}, F_{12}$, and Anjialing inverse fault and collapse columns do not affect the dump construction. Ning $\mathrm{Wu}$ incline situates the mining field boundary. The Anjialing anticline is found in the forwarding of the working line, the occurrence of two wings is inconsistent, the length of axis is about $6000 \mathrm{~m}$, the type is arc fold, and the direction of vertex is the southeast, as shown in Figure 6. The basement consists of mudstone, sandstone, and bedrock. The occurrence of the coal seam is from nearly horizontal to tilt, as shown in Figure 7(a). Stripping and constructing dump are carried out in the north of the first mining area to reduce the impact of anticline on mining and shorten transport distance, as illustrated in Figure 7(b). The drop of bedrock is about $250 \mathrm{~m}$, and the dip angle increases sharply to $24^{\circ}$ and then decreases gradually, as shown in Figure 8. The bumpy surface blasting method is used to increase the interface friction to improve the dump stability. The internal friction angle of the interface in the blasted area is greater than the originals. The development mode of the dump is construction of a bench to track the mining line.

3.2. Stability Analysis and Verification. Using the strength reduction method to calculate $F_{s}$ of the dumping step constructed in terms of the plot given in Figure 3(a) was performed. The parameters of rock mechanics and dump are, respectively, shown in Tables 1 and 2, and $c^{\prime}$ and $c^{0}$ are equal to $12000 \mathrm{~Pa}$, and $\varphi^{\prime}$ and $\varphi^{0}$ are equal to $20.5^{\circ}$ and $19^{\circ}$, respectively. $F_{s}$ was calculated with different $k$ and $j$ equal to 6. As shown in Figure $9, F_{s}$ rose with $k$ increasing, $k$ was not less than 0.9 , and $F_{s}$ increased obviously and tended to be 1.07. The following equation and plot were obtained by fitting the point in the graph:

$$
F_{s}=0 \cdot 99866+0 \cdot 0843 k-0 \cdot 00981 k^{2} .
$$

The curve had a better fit with the actual value. $F_{s}$ is a quadratic function of $k$ and increases with increasing $k$ and tends to be the constant value. The reason is that the friction of blasted bedrock is larger, and $F_{s}$ increases under the condition of constant sliding force. Because the shape of the 


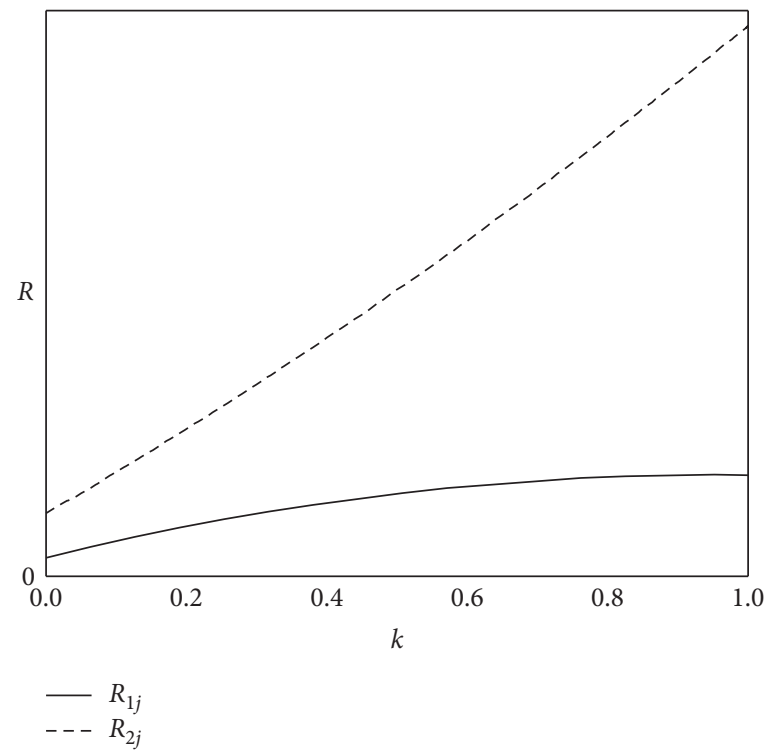

Figure 4: The relation between $R$ and $k$.

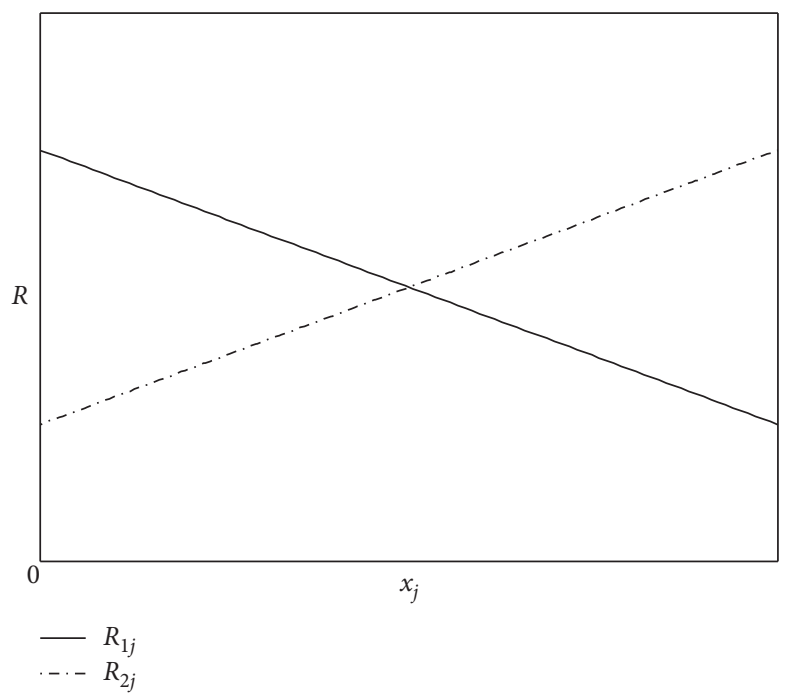

Figure 5: The relation between $R$ and $x_{j}$.

dumping bench shown in Figure 3(a) is triangular, the volume and gravity become smaller with $k$ increasing to 1 , so do the increment. Therefore, $F_{s}$ tends to be a constant value, and increment decreases with constant sliding force.

3.3. Deformation Behavior and Failure Mechanism. 28 and 19 displacement calculation nodes were arranged at the slope surface and platform with equal intervals, respectively; in the same way, 18 shear strain increment (SSI) calculation units on the bedrock. The formers were identified by ID with blue and the latter by No with red in Figure 10. The Lagrange difference method was adopted to calculate the displacement and plastic zone with different $k$ and $j$ equal to 6 . Figure 11 showed that deformation happened in I region, and the verticals mainly occurred at the middle area. Points identified by ID equal to 10 and 28 are turning points of horizontal and vertical displacement. $k$ was a constant value and not more than 0.3 , at the toe of dump steps, namely, when ID was not more than 10, displacement rose slightly with the height increasing. The horizontal displacement reached the maximum at the point identified by ID equal to 10 , the middle region of the step, that is, ID not less than 10 and not more than 28, the horizontal displacement diminished linearly, and the verticals increased, changing from $0.23 \mathrm{~m}$ and $0.17 \mathrm{~m}$ to $0.02 \mathrm{~m}$ and $0.01 \mathrm{~m}$, respectively with $k$ increasing, as shown in Figures 11(a) and 11(b). The verticals reached the peak at the spot numbered by ID equal to 28 , as shown in Figure 11(b). At the top area of the slope, the horizontal displacement and verticals sharply lessened with points identified by ID not less than 28 and not more than 35 and almost the same with ID not less than 35 . The vertical 


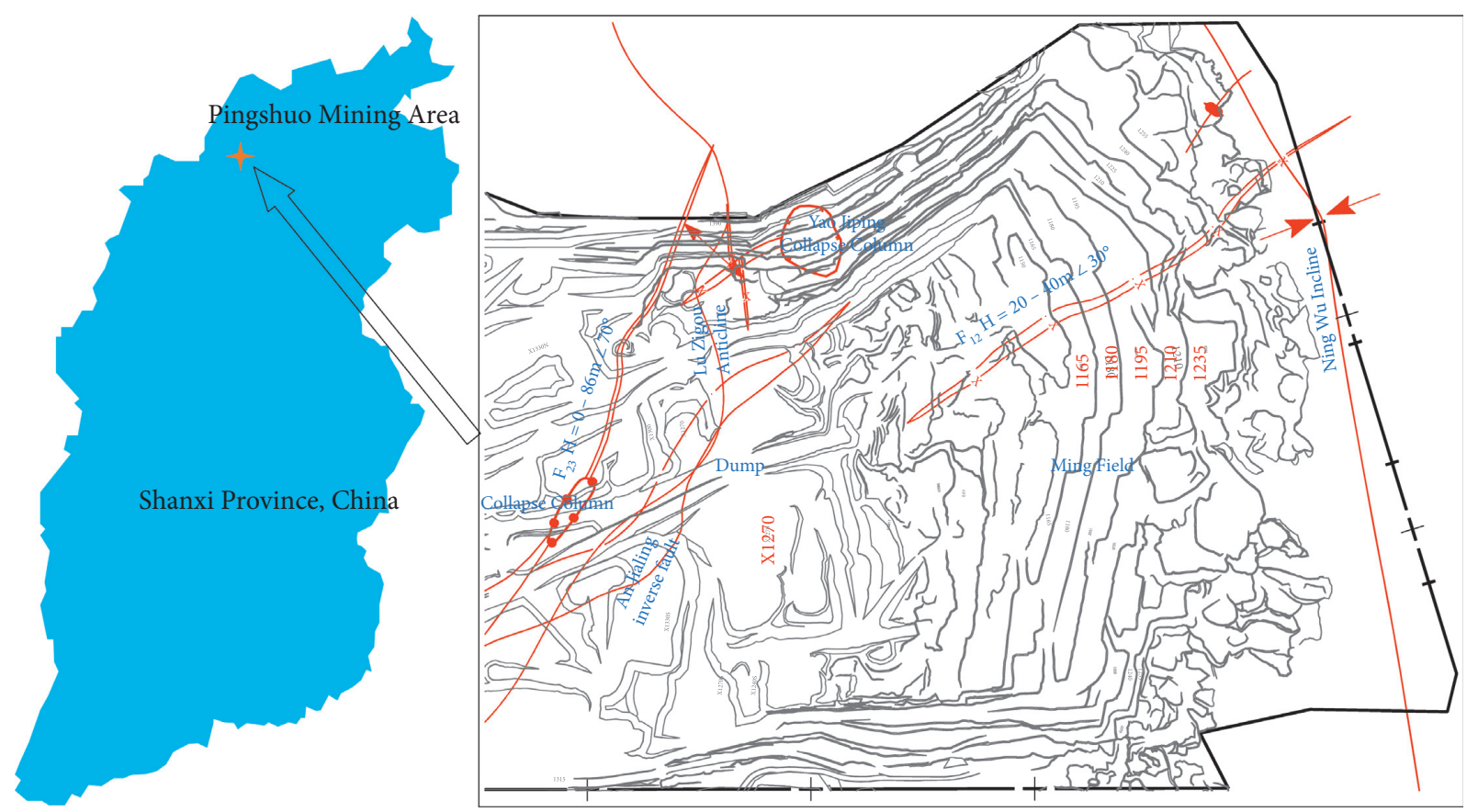

FIgURE 6: Geological structure at the $1^{\text {st }}$ mining area.
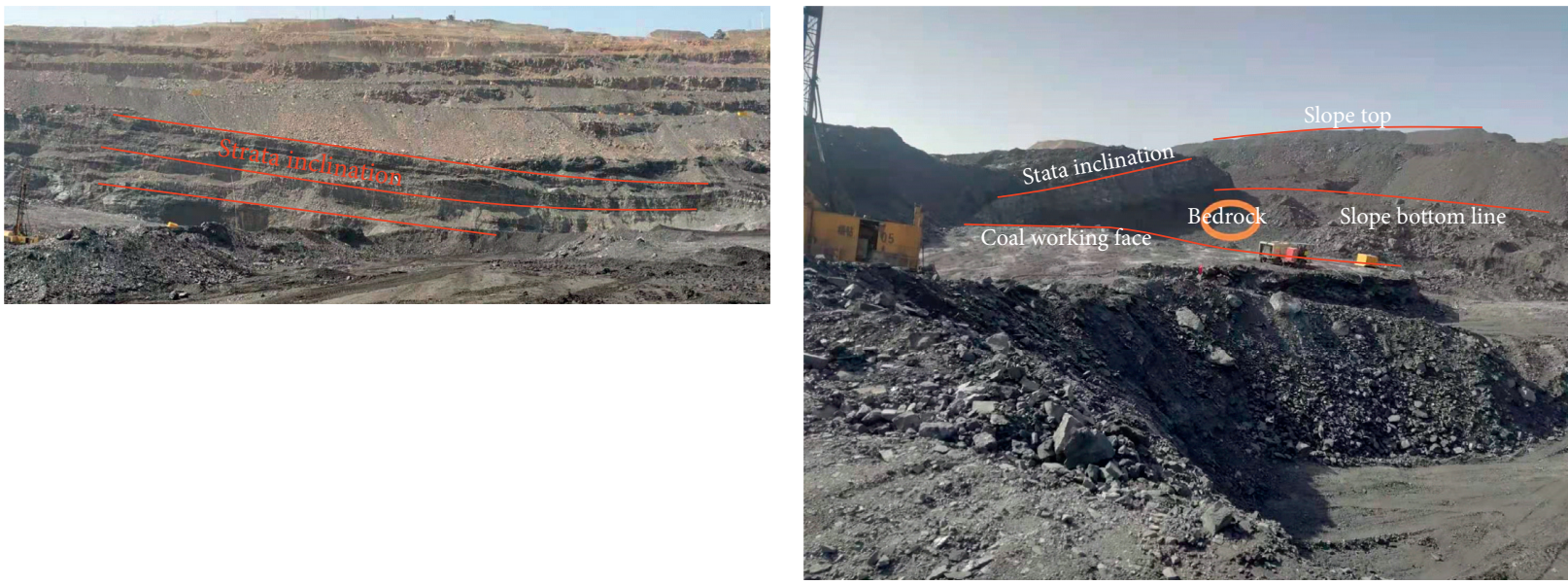

(a)

(b)

Figure 7: Spatial distribution of Lu Zigou anticline. (a) Inclination of rock. (b) Mining field and dump.

and horizontal displacements were nearly equal and changed slightly with $k$ not less than 0.3 , and node marked by ID more than 35 tended to be zero, about $0.01 \mathrm{~m}$. The displacement at the middle area was more easily affected by the value of $k$ than other regions.

As $k$ increases, the horizontal and the vertical displacement decreased, $k$ was greater than 0 , that is, the part of bedrock was blasted, the displacement sharply grew down, and the maximum of which changed from $0.23 \mathrm{~m}$ to $0.17 \mathrm{~m}$ with $k$ equal to 0 to $0.02 \mathrm{~m}$ and $0.01 \mathrm{~m}$, respectively. The variation of the horizontal displacement was greater than the verticals, and the deformation toward the free surface was limited by bumpy surface blasting. $k$ was more than 0.3 , the slope displacement changed smoothly, and the difference inclined to be 0 . Therefore, $k$ equal to 0.3 is an inflection point, and the horizontal and vertical displacement abruptly decreased and tended to a constant value, as shown in Figure 12.

The mechanical model of deformation and failure of the dump step overlying inclined bedrock was slipping-cracking along with the interface, and tensile fracturing only occurred at the top region, and the deformation was creeping, as shown in Figure 13. Also, there were many cracks at the dumping step flat surface in Anjialing Open-Pit Mine, as plotted in Figure 14. Creep occurring on a large scale resulted in tensile stress and cracking at the top of the slope, which led to the apparent subsidence in regions around nodes marked by ID equal to 28 , as illustrated in 


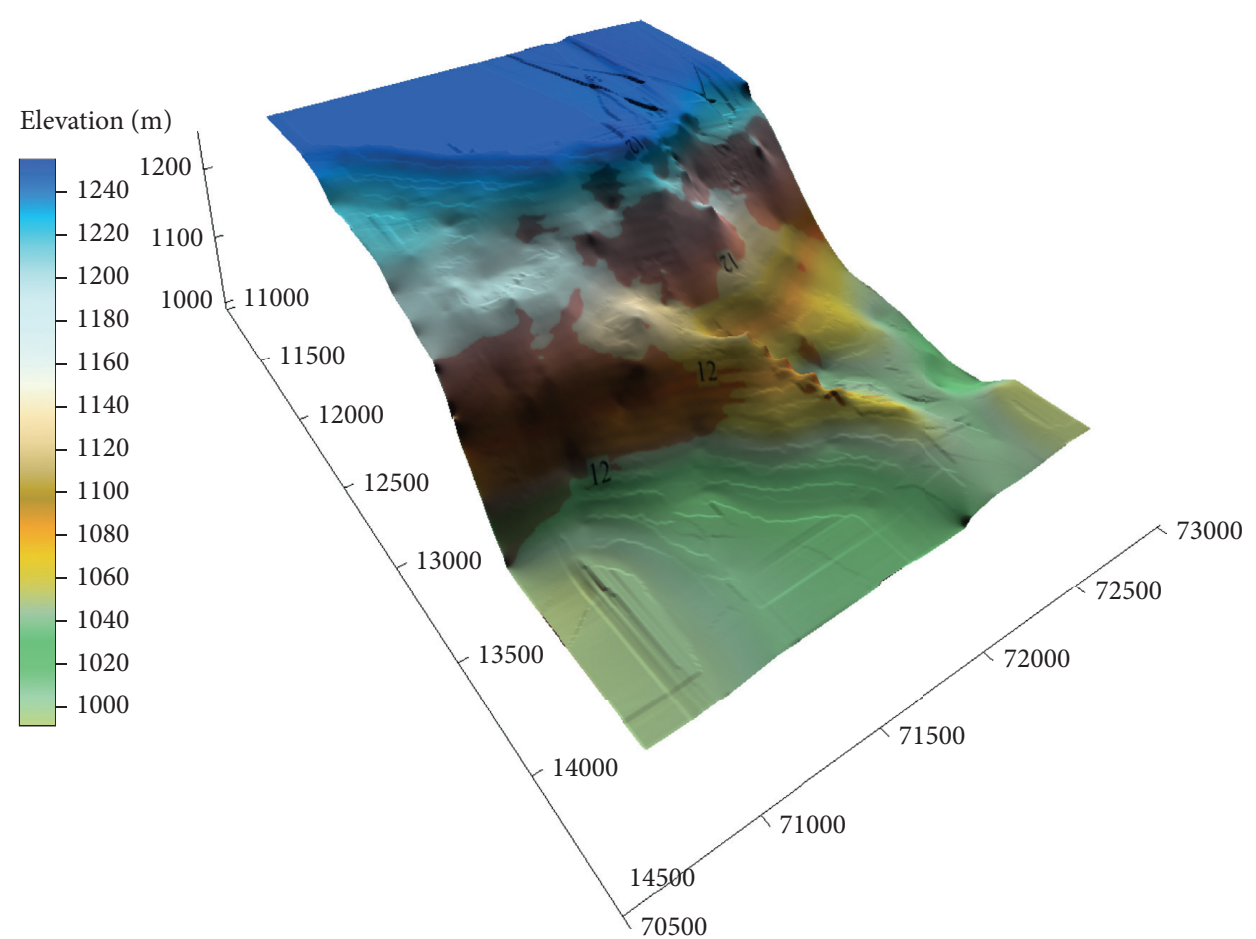

Figure 8: Elevation and slope of Lu Zigou anticline.

TABle 1: Parameters of rock mechanics.

\begin{tabular}{lcccrr}
\hline & $\rho\left(\mathrm{g} / \mathrm{cm}^{3}\right)$ & $c(\mathrm{KPa})$ & $\varphi\left(^{\circ}\right)$ & $E(\mathrm{GPa})$ & 0.0017 \\
\hline Dump & 1.99 & 25.6 & 22.4 & 0.1210 & 0.39 \\
Mudstone & 2.23 & 154.4 & 28.5 & 0.1950 & 0.31 \\
Sandstone & 2.3 & 361.5 & 27.1 & 0.22 \\
Bedrock & 2.29 & 122 & 29.6 & 0.20 & 0.25 \\
\hline
\end{tabular}

TABle 2: Parameters of dump.

\begin{tabular}{lccc}
\hline$H(\mathrm{~m})$ & $b(\mathrm{~m})$ & $\alpha\left(^{\circ}\right)$ & $\beta\left(^{\circ}\right)$ \\
\hline 30 & 60 & 16 & 35 \\
\hline
\end{tabular}

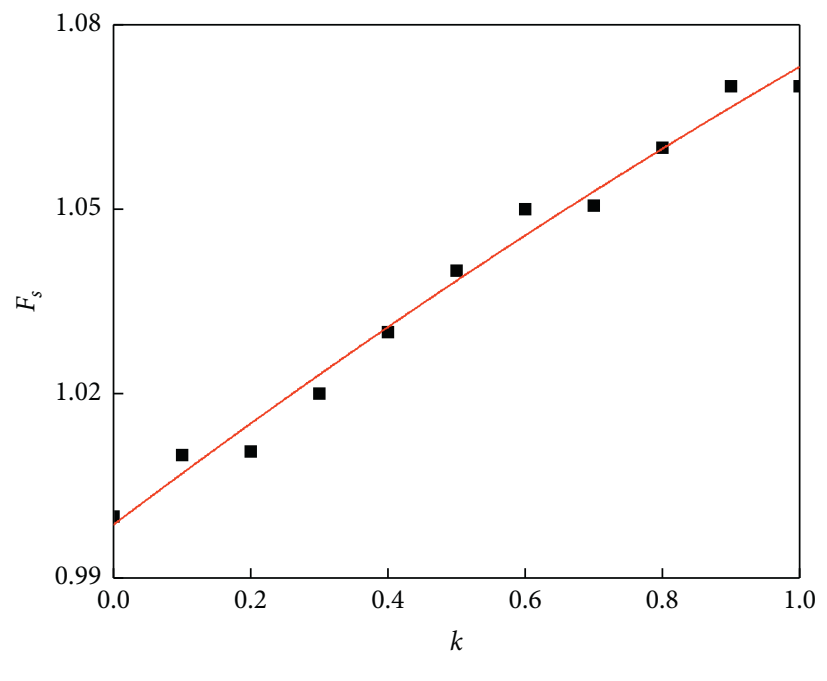

- $F_{s}$

Fitting curve of $F_{s} R^{2}=0.98201$

Figure 9: Variation of $F_{\mathrm{S}}$ with different $k$ values. 


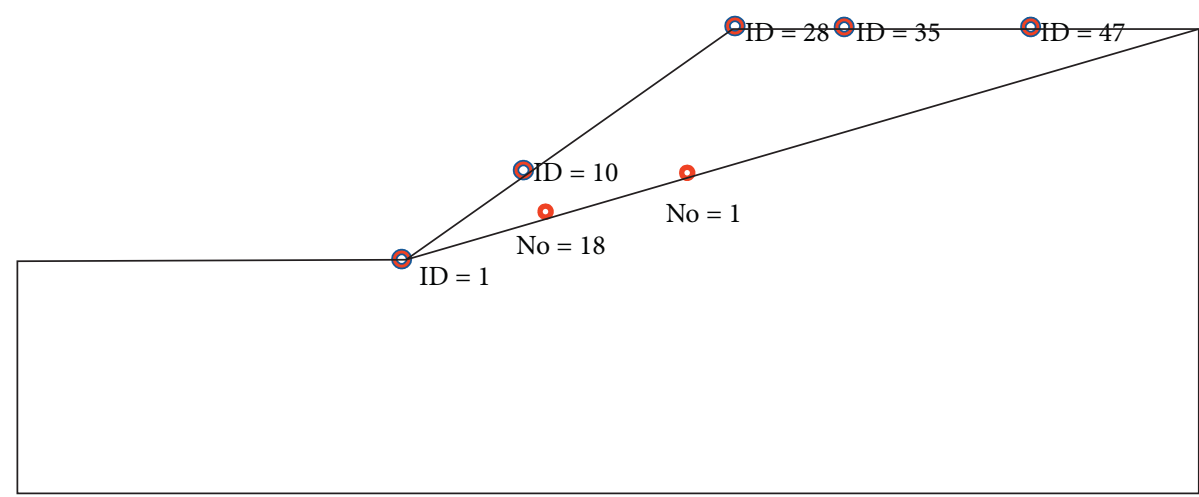

Figure 10: Distribution of calculation points.

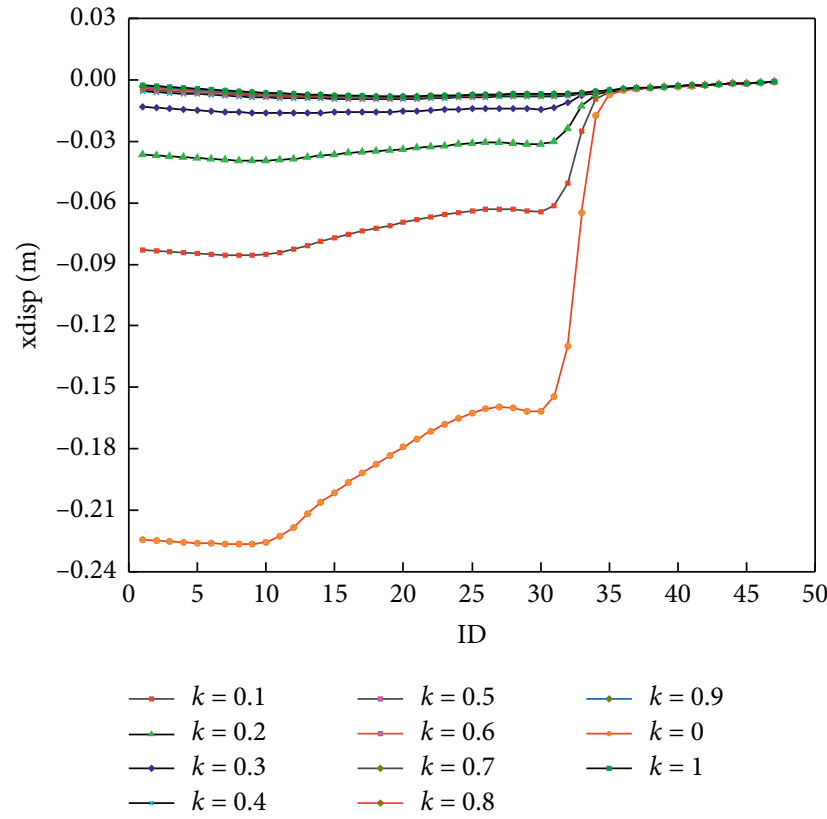

(a)

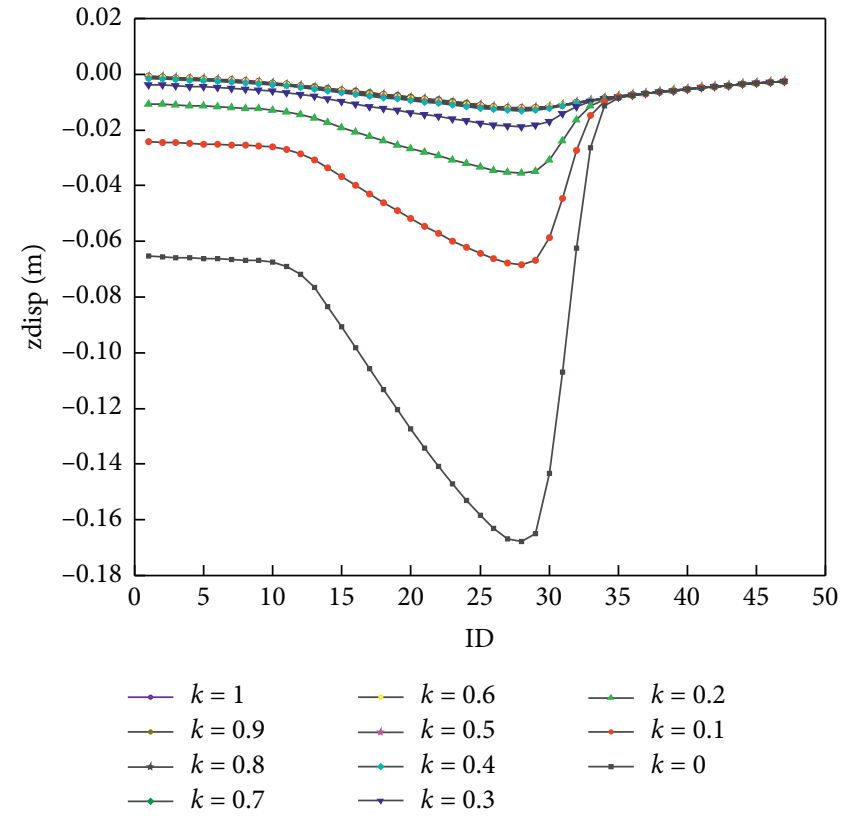

(b)

Figure 11: Displacement of the slope. (a) Horizontal displacement. (b) Vertical displacement.

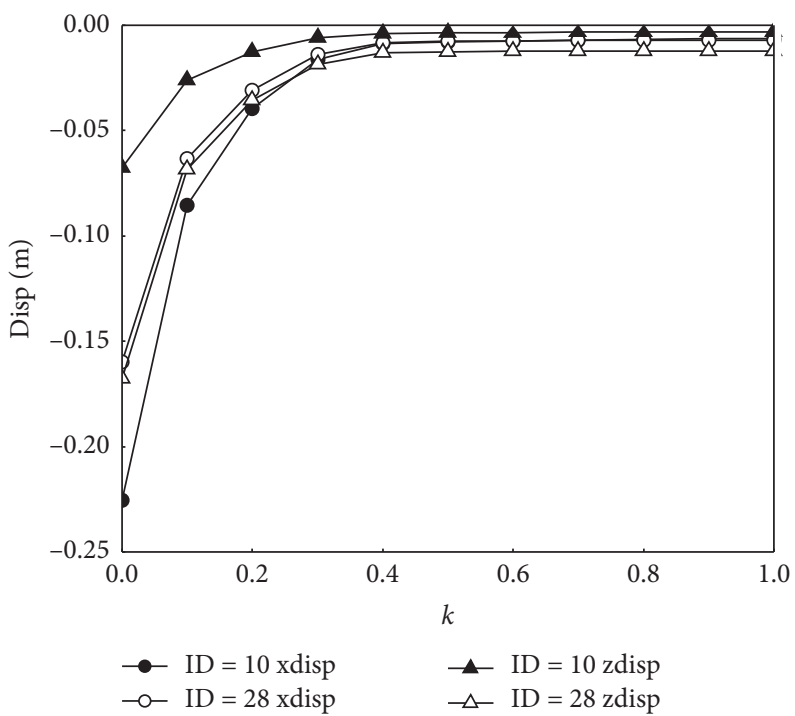

Figure 12: The displacement of the special point with $k$. 


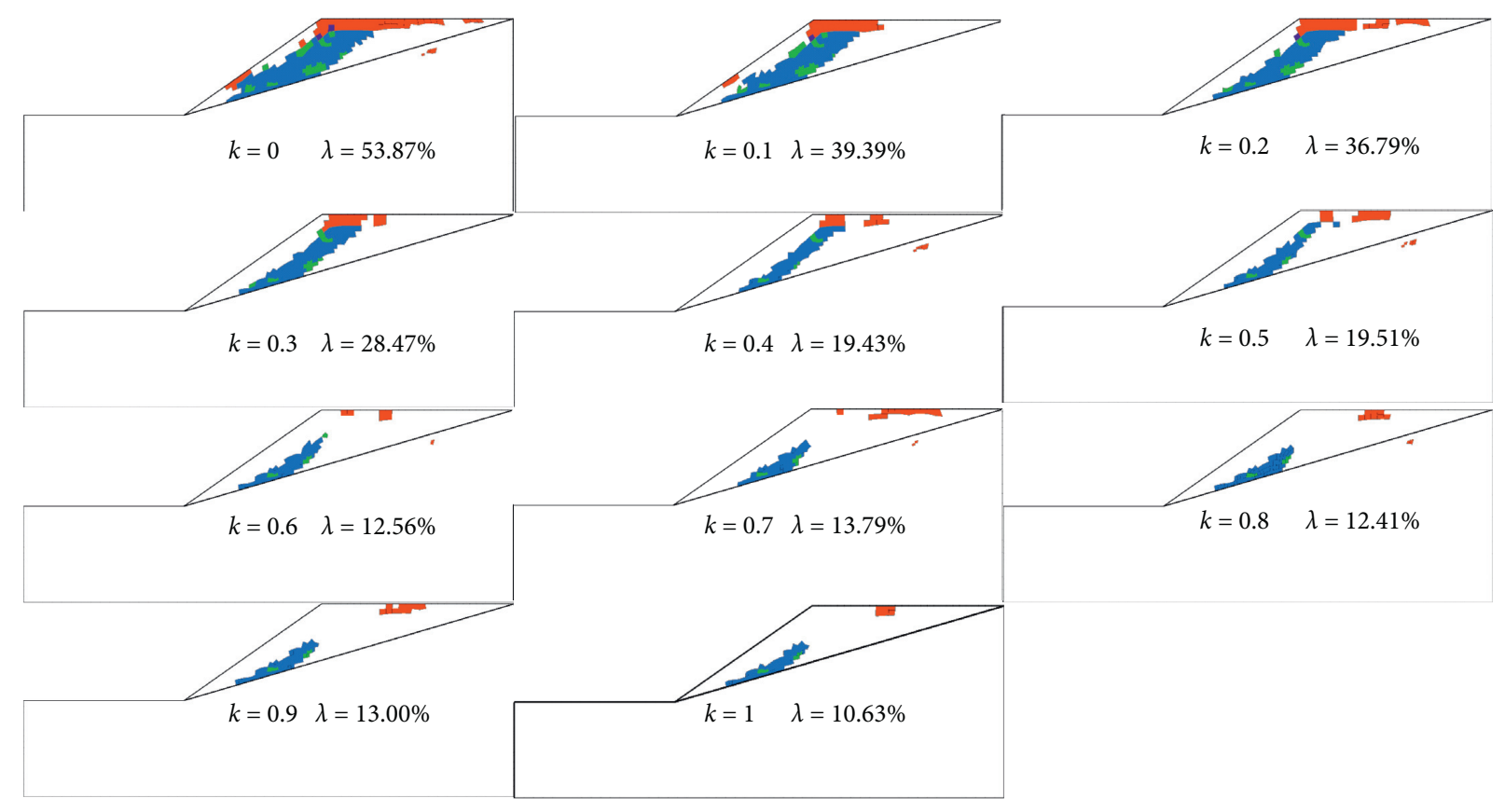

Tension failure

Shear failure

FIgURE 13: Failure mode.
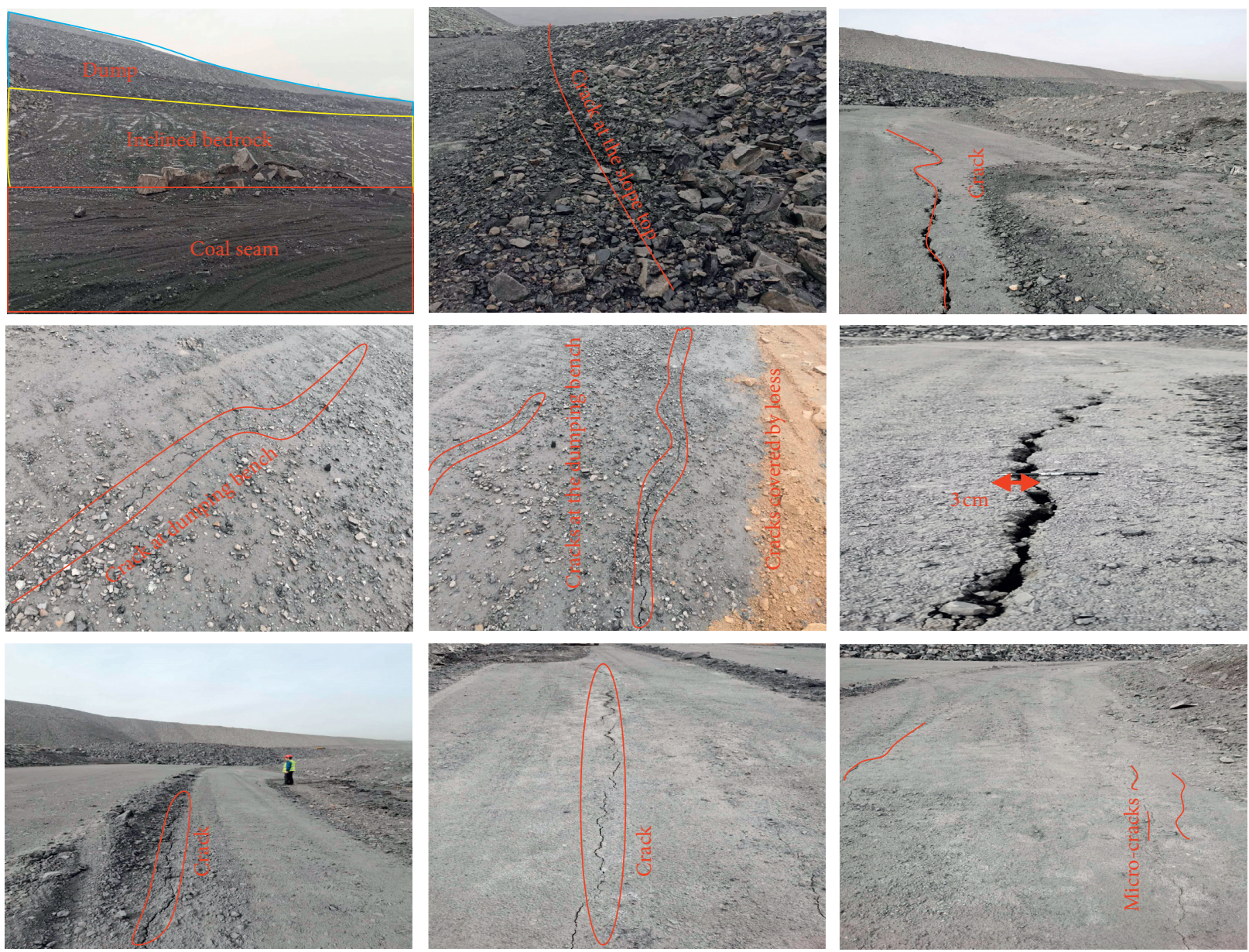

FIgURE 14: Cracks of dump at large inclined substrate. 


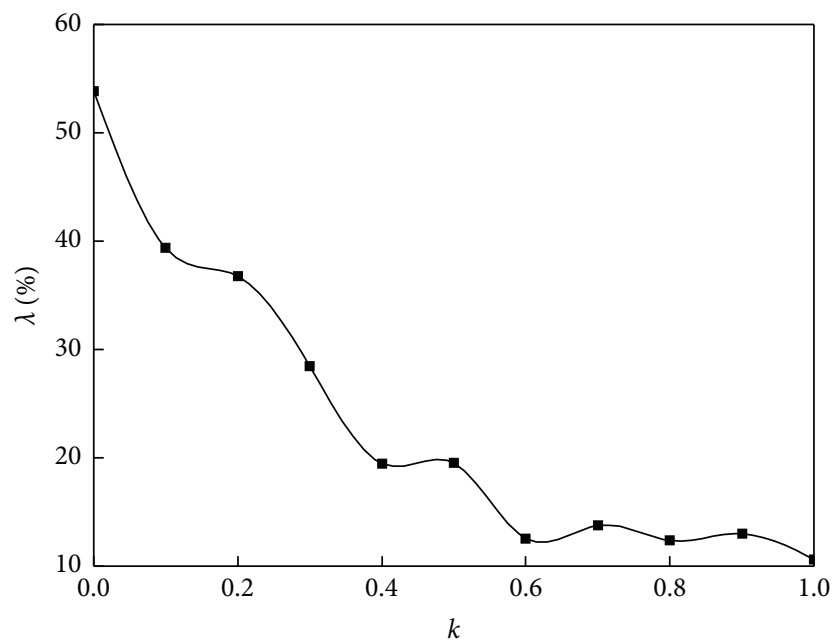

Figure 15: The variation of $\lambda$ with $k$.

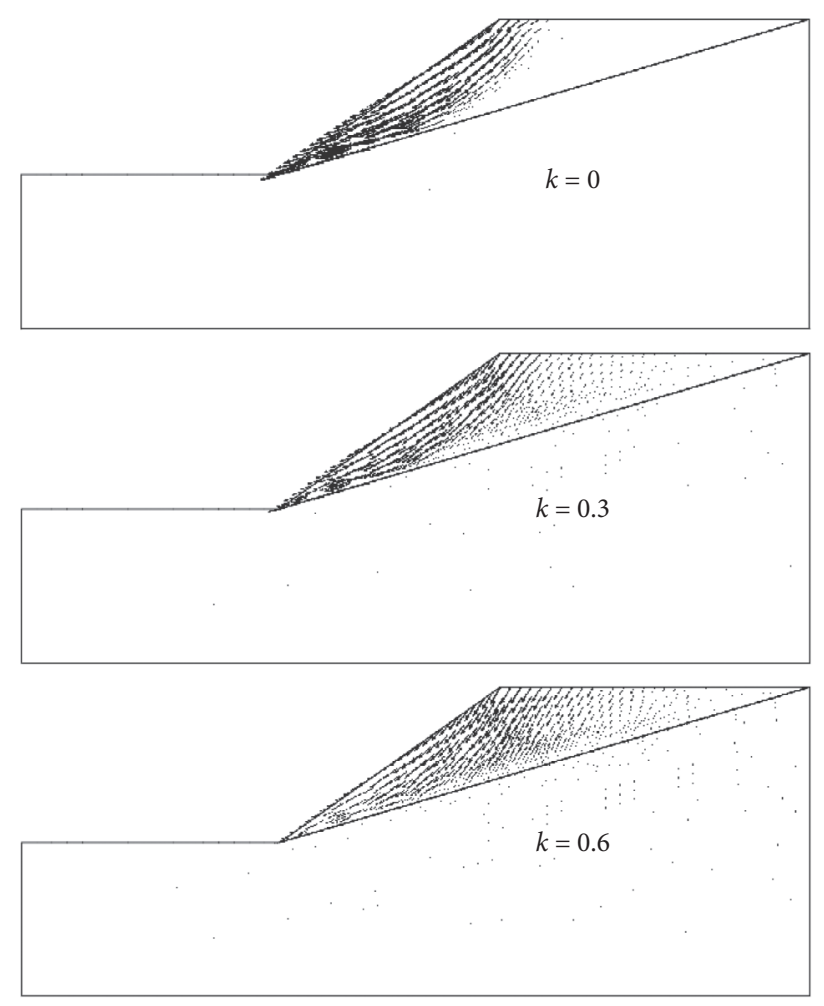

FiguRE 16: Displacement vector.

Figure 11(a). There was a connection between the shear and tensile failure area with $k$ equal to 0 , and the area of failure zones decreased. As $k$ was less than 0.3 , the failure mode of dumping berm was tensile failure, and the tensile plastic zones covered the whole platform. The tensile and shear failure zones further significantly shrank as $k$ increased; however, there was an upper limit to make the two types of plastic zones no longer connected. The tensile failure zones almost disappeared, and the shear failures were nearly unchanged. $\lambda$ decreased sharply from $53.87 \%$ to $12.56 \%$ with $k$ increasing from 0 to 0.6 , changed slightly and tended to a constant with $k$ not less than 0.6 , as shown in Figure 15 . The variation of shear and tensile failure elements meant that the bumpy surface blasting method can effectively change the stress distribution of the bench and reduce the sliding possibility.

The deformation direction of steps was different with various values of $k$ and that of the upper part changed from being parallel to the slope to pointing inside gradually, and the toe of the slope from pointing outwards to being parallel 


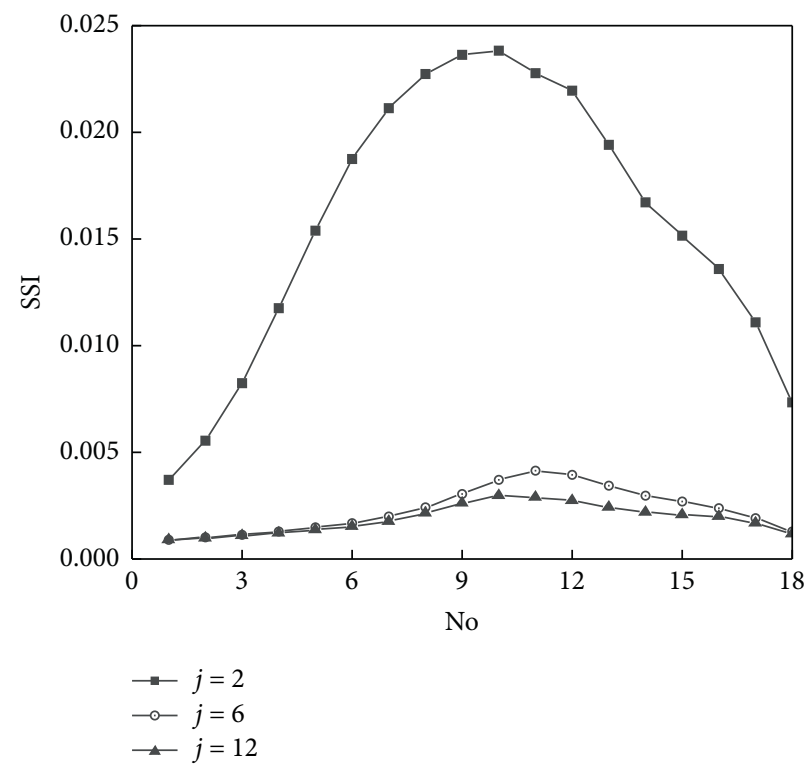

FIGURE 17: Shear strain increment of bedrock.

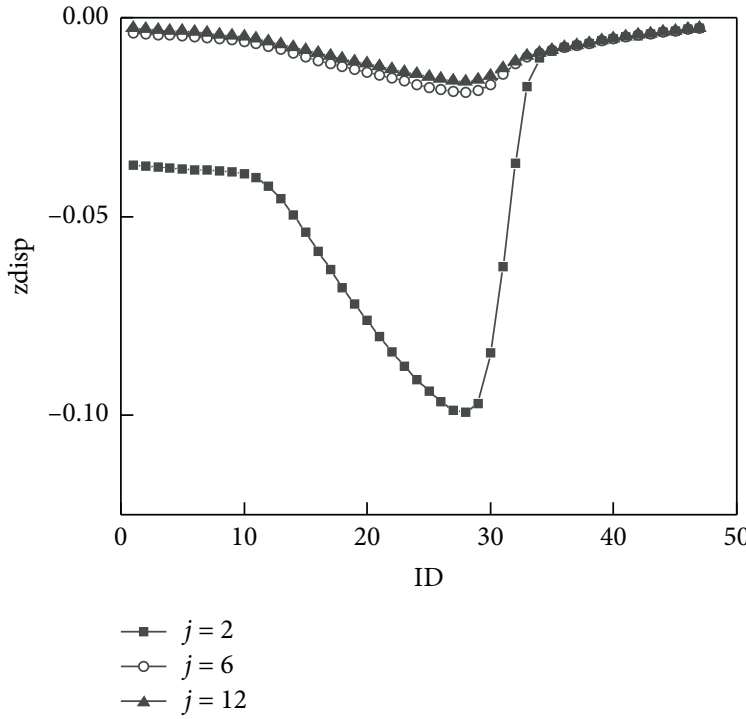

(a)

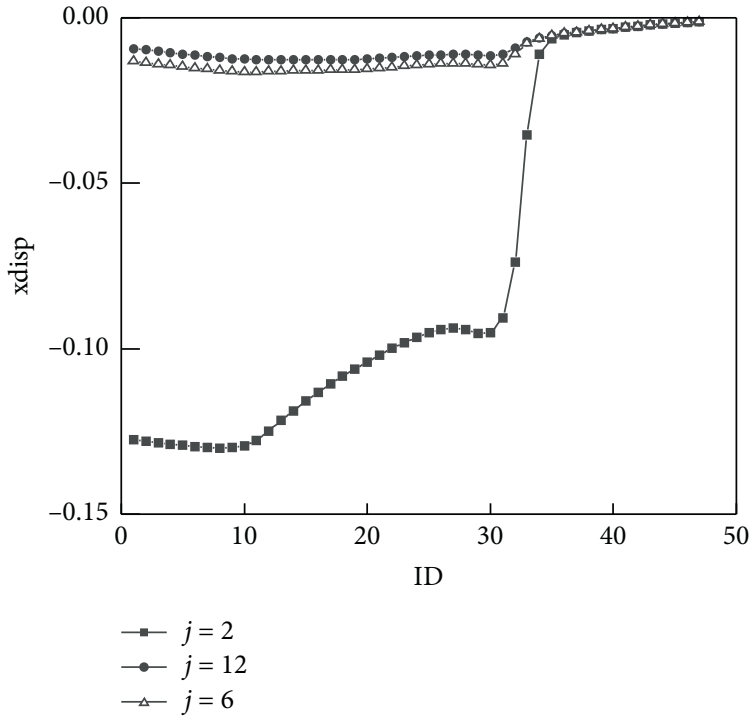

(b)

Figure 18: Displacement of the dumping step. (a) Vertical displacement. (b) Horizontal displacement.

to the surface, as shown in Figure 16. The result demonstrated that the deformation was significantly changed by modifying the bedrock structure.

The deformation and variation of the plastic zone were sensitive to $k$. The number of blasted groups $(j)$ significantly changed the displacement as $k$ was constant and equal to 0.3 , and the shear strain increment (SSI) sharply decreased from $2.4 e-2$ to $3 e-3$ with $j$ growing from 2 to 12 , and the SSI would be small, and the curve tended to be horizontal as $j$ increased to be a specific value, as shown in Figure 17. The SSI variation indicated that the failure along the interface occurred in a specific area and the position does not change, which is also illustrated by Figure 12. The increase of $j$ made the SSI tend to a specific value, and the failure mode transformed. It can be seen from Figures 18(a) and 18(b) that $j$ alike $k$ affected the variation of displacement, and the direction was not changed.

\section{Discussion}

The basement blasted by bumpy surface blasting can significantly improve the stability of dump constructed in large inclined regions. Compared with the retaining pillar, the method is characteristic of no compressing coal, simple mining procedure, small stripping ratio, and lower cost than cable reinforcement. From the perspective of the blasting 
design, Fenglin et al. analyzed the changes in the shape of the blasted basement and the overdrilling value under different charge depths and determined the charging quantity, hole, and row spacing. They did not take the ratio and dispersion degree of the blasted region into consideration, from which this paper explored deformation and failure characteristics and further improved the method of dumping with anticline in the open-pit mine. The increase of $k$ and $j$ makes the displacement sharply decrease, and the deformation direction and mechanical failure mode both change. The area of tensile and shear failure lessens sharply and tends to a fixed value as $k$ increases. The two areas are not linked as $k$ is equal to 0.6 , and the displacement is minimal as $k$ is equal to 0.3 . The deformation direction varies with different $k$. Therefore, an appropriate $k$ value should be selected in dump projects.

There are some open-pit mines in the northeast and southwest of China marked by intense rainfall. The research on stability of dump constructed at the steep area under the condition of rainfall, especially rainstorms, should be strengthened. In the process of open-pit mining, the mining and dumping cannot be conducted simultaneously in a certain area, the laws of which should be further studied to provide sufficient friction force for the dump with bedrock inclined.

\section{Conclusions}

The internal dump stability with the inclined basement can be improved by processing bedrock through bumpy surface blasting. The effect of the ratio and dispersion degree of blasted zones on the deformation and failure in the large inclined area was analyzed based on the shear strength reduction and Lagrangian difference methods. The main conclusions are drawn as follows.

(1) The bumpy surface blasting was suitable for constructing dump in open-pit mines located in dry and rainless areas without groundwater, improved the stability and restrain deformation and failure of the dump with large inclined bedrock, shortened the transport distance, and reduced the production cost.

(2) The antisliding force was a linear function of the blasting position, and the factor of stability was a quadratic function of the ratio of the blasted area, which increased with the ratio increasing and tended to a constant value.

(3) The deformation of the dumping steps at the steeply inclined area was significantly affected by the blasted zone ratio, and the displacement with blasted bedrock decreased sharply. The horizontal displacement was more susceptible to the ratio than the verticals. There was a special value for the ratio, which made the displacement decrease abruptly, and greater than the value, the displacement almost unchanged. The method changed the deformation direction from pointing out of the slope to paralleling to the slope surface. The zone of tensile and shear failure sharply decreased with the ratio increasing.
(4) With the dispersion degree of the blasted area increasing, the displacement was effectively reduced, and the deformation failure mode was changed. There is an inflection point which made the deformation and failure mode from creep-cracking to creep.

\section{Data Availability}

The data used to support the findings of this study are available within the article.

\section{Conflicts of Interest}

The authors declare that there are no conflicts of interest regarding the publication of this paper.

\section{Acknowledgments}

This work was supported by the Open Fund of State Key Laboratory for GeoMechanics and Deep Underground Engineering, China University of Mining and Technology (Beijing) (SKLGDUEK1923), and National Key Research and Development Project (2018YFC0808301).

\section{References}

[1] A. Paithankar, S. Chatterjee, and R. Goodfellow, "Open-pit mining complex optimization under uncertainty with integrated cut-off grade based destination policies," Resources Policy, vol. 70, Article ID 101875, 2021.

[2] W. Yu, B. Pan, F. Zhang, S. Yao, and F. Liu, "Deformation characteristics and determination of optimum supporting time of alteration rock mass in deep mine," KSCE Journal of Civil Engineering, vol. 23, no. 11, pp. 4921-4932, 2019.

[3] F. Wang, J. Wang, and Y. Wang, "Using multi-fractal and joint multi-fractal methods to characterize spatial variability of reconstructed soil properties in an opencast coal-mine dump in the Loess area of China," Catena, vol. 182, Article ID 104111, 2019.

[4] Z. Hongze, W. Dongyu, M. Ming, and Z. Kaihui, "Parameter inversion and location determination of evolutionary weak layer for open-pit mine slope," International Journal of Coal Science \& Technology, vol. 7, no. 4, pp. 714-724, 2020.

[5] C. Lanni, J. McDonnell, L. Hopp, and R. Rigon, "Simulated effect of soil depth and bedrock topography on near-surface hydrologic response and slope stability," Earth Surface Processes and Landforms, vol. 38, no. 2, pp. 146-159, 2013.

[6] S. Moradi, J. A. Huisman, H. Class, and H. Vereecken, "The effect of bedrock topography on timing and location of landslide initiation using the local factor of safety concept," Water, vol. 10, no. 10, p. 1290, 2018.

[7] G. J. C. Gomes, J. A. Vrugt, E. A. Vargas, J. T. Camargo, R. Q. Velloso, and M. T. van Genuchten, "The role of uncertainty in bedrock depth and hydraulic properties on the stability of a variably-saturated slope," Computers and Geotechnics, vol. 88, pp. 222-241, 2017.

[8] Y. Y. Zhao, G. Zhang, D. S. Hu, and Y. Z. Han, "Centrifuge model test study on failure behavior of soil slopes overlying the bedrock," International Journal of Geomechanics, vol. 18, no. 11, p. 11, 2018.

[9] B. A. Clarke and D. W. Burbank, "Bedrock fracturing, threshold hillslopes, and limits to the magnitude of bedrock 
landslides," Earth and Planetary Science Letters, vol. 297, no. 3-4, pp. 577-586, 2010.

[10] M. Miraboutalebi, F. Askari, and O. Farzaneh, "Effect of bedrock inclination on seismic slope stability according to Iran seismically data," International Journal of Civil Engineering, vol. 9, no. 4, pp. 247-254, 2011.

[11] A. Mahanta, R. Bhowmik, and M. Datta, "Stabilization of hazardous solid waste landfill on sloping ground with variable base inclination," in Proceedings of the Eighth International Conference on Case Histories in Geotechnical Engineering (GSP 312), Philadelphia, PA, USA, March 2019.

[12] T. D. Stark, W. D. Arellano, R. P. Hillman, R. M. Hughes, N. Joyal, and D. Hillebrandt, "Effect of toe excavation on a deep bedrock landslide," Journal of Performance of Constructed Facilities, vol. 19, no. 3, pp. 244-255, 2005.

[13] A. A. Zaitseva, V. I. Cheskidov, and G. D. Zaitsev, "Effect of the mining sequence on the internal dump capacity in an open pit," Journal of Mining Science, vol. 43, no. 5, pp. 508-515, 2007.

[14] H. Liu, J. Shu, Q. Cai, H. Jing, and H. Tian, "Mechanical characteristics of dip basement effects on dump stability in the Shengli open pit mine in Inner Mongolia, China," Arabian Journal of Geosciences, vol. 9, no. 20, p. 13, 2016.

[15] D. Wang, L. Guanghe, C. Lanzhu, B. Runcai, and S. Ziling, "Mechanical effect of supporting and retaining coal pillar on internal waste dump with weak basement," Journal of China Coal Society, vol. 44, no. 3, pp. 934-941, Article ID 55945743, 2019.

[16] E. A. Sorochan and A. M. Puzrin, "Calculation of an inclined foundation with anchors for building on a slope," Soil Mechanics and Foundation Engineering, vol. 29, no. 2, pp. 46-52, 1992.

[17] B. R. Rakishev, O. M. Shashenko, O. S. Kovrov, and G. K. Samenov, "Estimating stability of internal overburden dumps on the inclined foundation by simplified bishop criterion," Proceedings of the 12th International Symposium Continuous Surface Mining-Aachen 2014, Springer-Verlag, Berlin, Germany, pp. 127-135, 2015.

[18] F. Dong and G. Zhang, "A study on the application of the bumpysurface blasting method," Journal of Fu Xin Ming Institute, vol. 7, no. 2, pp. 95-102, 1988. 